\title{
Property analysis of throttle rubber material under high temperature and high pressure in Sulige gas field
}

\author{
YanJie $\mathrm{Yu}^{1, a^{*}}$, Dan $\mathrm{Pan}^{2}$, ChuanJie Jiang ${ }^{2}$, XiaoJiang $\mathrm{Liu}^{2}$ and Pan $\mathrm{Li}^{3}$ \\ ${ }^{1}$ No.3 Gas Production Plant, PetroChina Changqing Oilfield Company \\ ${ }^{2}$ No. 5 Gas Production Plant, PetroChina Changqing Oilfield Company \\ ${ }^{3}$ No.2 Gas Production Plant, PetroChina Changqing Oilfield Company \\ ayyjie_cq@petrochina.com.cn
}

Keywords: property analysis; throttle rubber material; high temperature; high pressure

\begin{abstract}
The downhole throttle technology is wildly used in Sulige gas field which was low voltage, low yield. To evaluate the service performance of throttle, property analysis of throttle rubber material under high temperature and high pressure in Sulige gas field was researched in this paper. An autoclave was used to produce the high temperature and high pressure environment. The experiment data, such as the change of hardness, tensile strength, elongation at break, $50 \%$ elongation, tear strength, change rate of tear strength, mass change rate and volume change rate, were tested. The results show that the throttle rubber material is not too bad for service in Sulige gas field.
\end{abstract}

\section{Introduction}

The downhole throttle technology is wildly used in Sulige gas field which was low voltage, low yield. Downhole throttling technology is the domestic and is wildly used in foreign oil and gas fields in recent years. It is a new technology to promote the gas field development of economy and efficiency. Because it is not only realized the well throttle pressure, but also reduced the ground construction investment. And it is an effectively solve the frequent plugging protection caused by the formation of hydrate in the wellbore. To ensure the smooth production of gas well, many downhole throttles were wildly used in Sulige gas field. But some new problems were raised, the life of the throttle and the loss caused by the failure[1-2].

Throttle rubber material plays an important role for service performance of the throttle. Thus, a series of experiments was carried out in high temperature and high pressure environment. The purpose of the experiment is to understand the performance requirements of rubber materials by high temperature and high pressure corrosion test of rubber materials. High temperature and high pressure corrosion experiment of four groups of samples and test samples before and after change of hardness value, and the rate of change of the tensile strength and elongation change, $50 \%$ constant extension rate of change of intensity, and the rate of change of the tear strength, rate of change of mass and volume change rate of experimental data[3-4].

\section{Experiments and Discussion}

(1) Rubber resistant liquid test

Rubber liquid resistance experiment was tested by using FCZ3 Hastelloy alloy which provided the high-pressure reaction kettle (design pressure $27 \mathrm{Mpa}, 450^{\circ} \mathrm{C}$ ). In autoclave inlet, the GYZ25 type high-pressure air pump was installed, T911Y-320C forging type electric pressure regulating air valve was installed. 


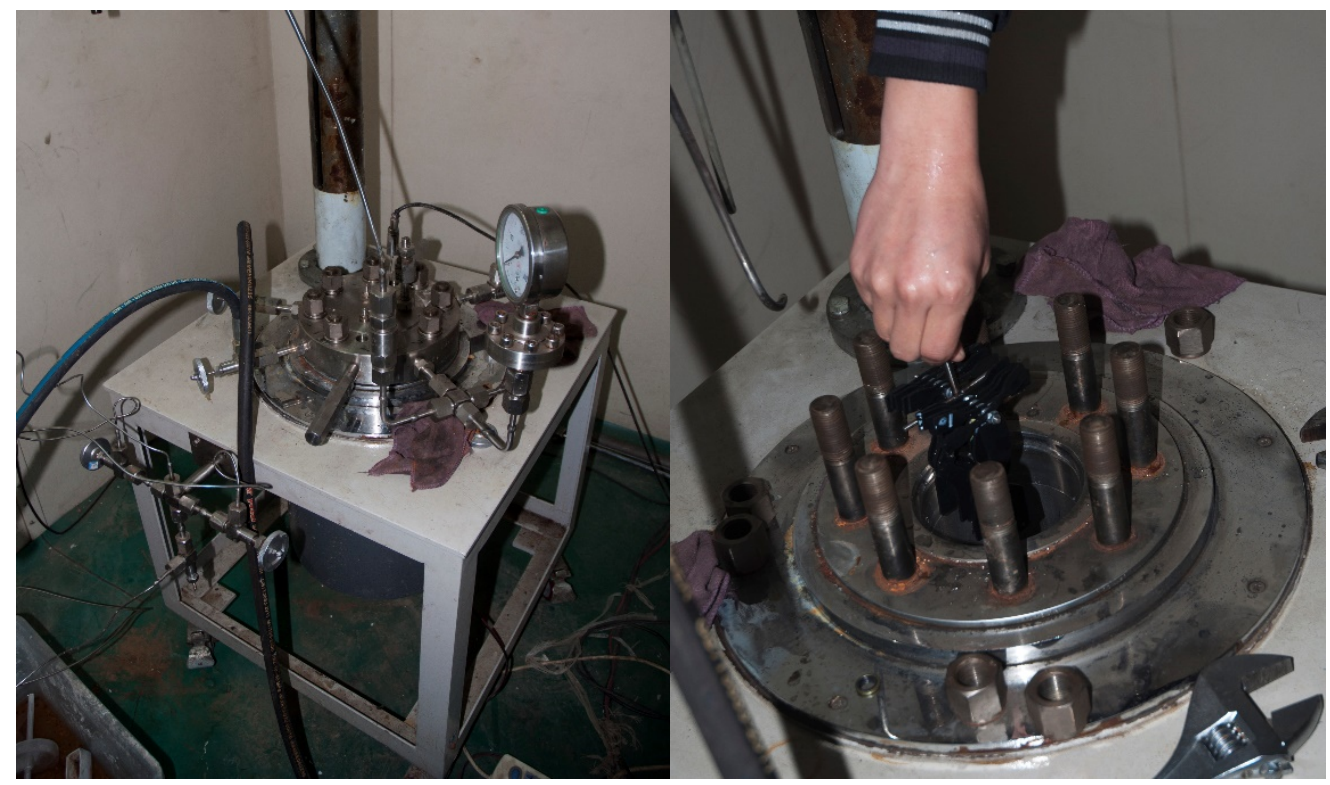

Fig. 1 High pressure autoclave for rubber resistance liquid test

(2) Rubber quality and density measurement

The ES120D density balance(accurate to 1mg) was using to test the quality of rubber samples before and after the liquid test, the quality of the water in the water.
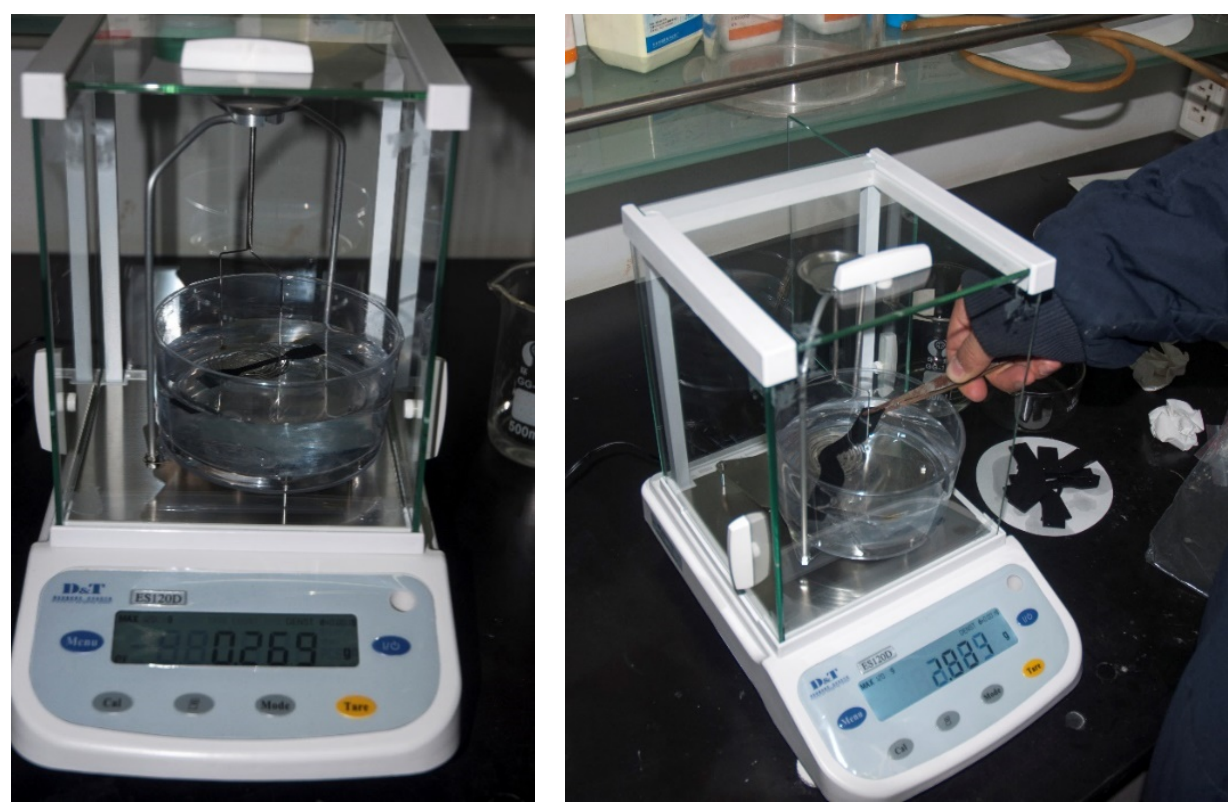

Fig. 2 Schematic diagram of the test of the quality of the sample in liquid

$\Delta m_{100}=\frac{m_{i}-m_{0}}{m_{0}} \times 100 \%$

$\Delta V_{100}=\left(\frac{m_{i}-m_{i, w}+m_{s, w}}{m_{0}-m_{0, w}+m_{s, w}}-1\right) \times 100 \%$

$m_{0}$ : Quality of sample in air before immersion, $\mathrm{g}$

$m_{i}$ : Quality of sample in air after immersion, g

$m_{0, w}$ : Quality of sample in water before immersion, g 
$m_{i, w}$ : Quality of sample in water after immersion, g

$m_{s, w}:$ Pendant in water quality, g

(3) Mechanics property test of rubber

Measurement of tensile strength and tear strength of rubber samples using WDW-1 electronic tensile testing machine.

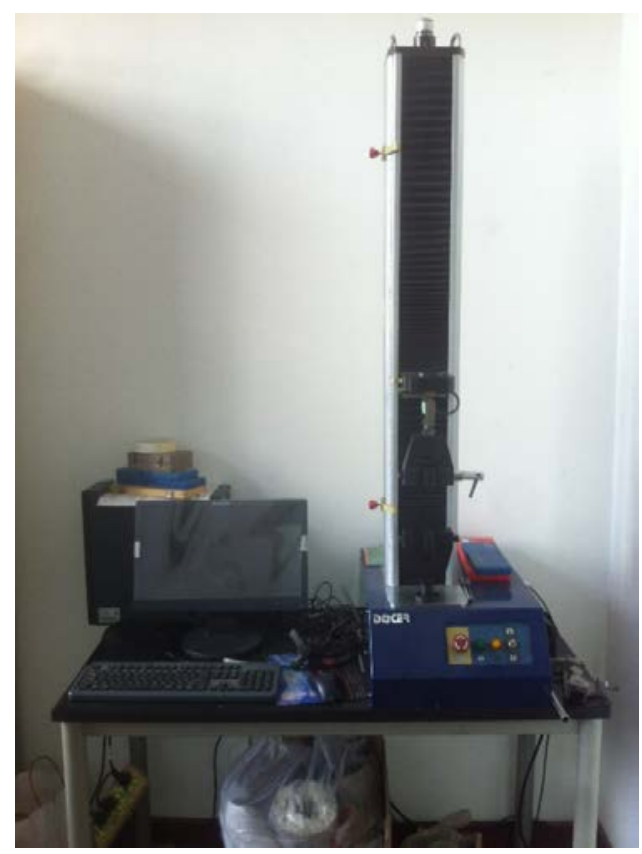

Fig. 3 WDW-1 electronic tensile testing machine

$$
\Delta X=\left(X_{i}-X_{0}\right) / X_{0} \times 100 \%
$$

The rate of change of tensile strength, the rate of change of elongation, the rate of change of $50 \%$, the change rate of $100 \%$ and tear strength, were calculated.

(4) Experiments result discussion

Tab. 1 Tensile and tear properties of rubber samples under different experimental conditions

\begin{tabular}{|c|c|c|c|c|c|c|}
\hline $\begin{array}{c}\text { Serial } \\
\text { number }\end{array}$ & $\begin{array}{c}\text { tensile } \\
\text { strength } \\
\text { MPa }\end{array}$ & $\begin{array}{c}\text { Change } \\
\text { ratio of } \\
\text { tensile } \\
\text { strength } \\
\%\end{array}$ & $\begin{array}{c}\text { elongation } \\
\%\end{array}$ & $\begin{array}{c}\text { Elongation } \\
\text { rate } \\
\%\end{array}$ & $\begin{array}{c}\text { tear } \\
\text { strength } \\
\mathrm{KN} / \mathrm{m}\end{array}$ & $\begin{array}{c}\text { change rate of } \\
\text { Tear trength } \\
\%\end{array}$ \\
\hline 1 & 13.61 & 0 & 555.54 & 0 & 70.69 & 0 \\
\hline 2 & 5.47 & -59.82 & 293.74 & -47.13 & 41.11 & -41.85 \\
\hline 3 & 2.026 & -85.11 & 120.86 & -78.24 & 10.47 & -85.18 \\
\hline 4 & 0.42 & -96.89 & 107.42 & -80.66 & 2.89 & -95.91 \\
\hline 5 & 15.31 & 0 & 482.38 & 0 & 71.27 & 0 \\
\hline 6 & 7.81 & -49.02 & 284.12 & -41.10 & 46.44 & -34.83 \\
\hline 7 & 2.54 & -83.43 & 131.24 & -72.79 & 11.62 & -83.70 \\
\hline 8 & 0.45 & -97.05 & 115.37 & -76.08 & 3.134 & -95.60 \\
\hline 9 & 0.106 & -99.31 & 26.86 & -94.43 & 1.20 & -98.31 \\
\hline
\end{tabular}




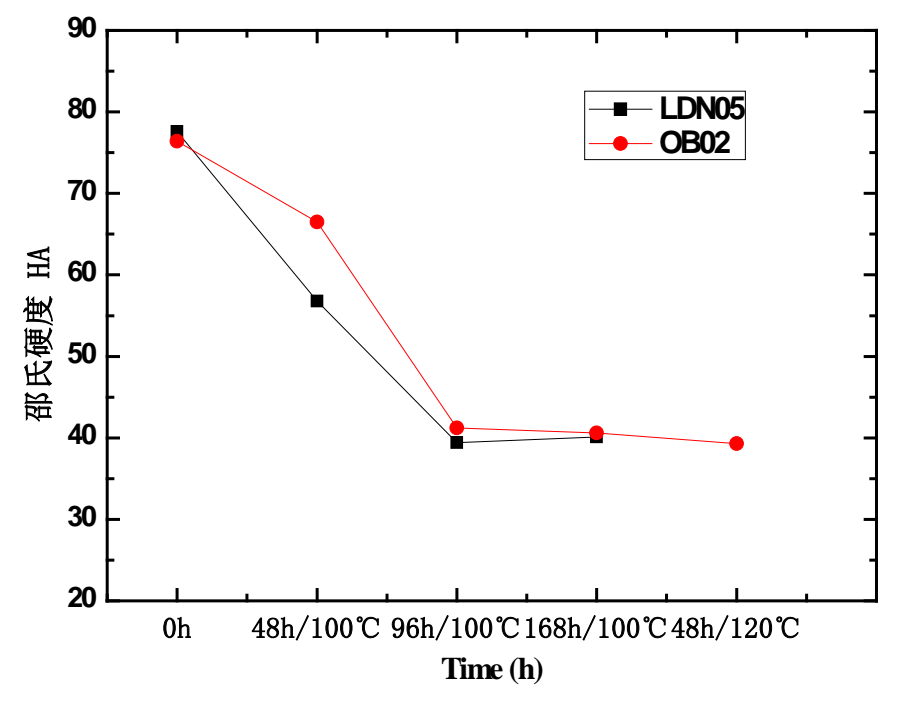

Fig. 4 the changes of shore hardness with different soaking time

\section{Summary}

The results show that the soaking time and soaking temperature are sensitive factors to the performance of rubber materials, and the increase of temperature is the most influential factor to the performance of the sample. The two groups of rubber in a predetermined experimental environment neutral can be decreased seriously, in addition to the rubber materials at 120 DEG C and 27mpa, 48h experimental liquid resistance still retains good performance outside, other sets of experiments results are expressed rubber has been unable to continue to use.

\section{References}

[1] LI Guomei, WANG Yueshe, SUN Hu, KANG Liqiang, et al. Numerical simulationon solid particle erosion of solid-liquid two-phase fluid in flow controller[J], ACTA PETROL EI SINICA. 2009, 30(1):145-148.

[2] Humphrey J A C. Fundamentals of fluid motion in erosion by solid particle impact[J]. International Journal of Heat and Fluid Flow, 1990, 11(3) :170-195.

[3] XIAOShu-qin, YUZhi-gang, SHANGYong-bin, WEIYa-ming, YANGXu-dong, Development and Application of Fishing Tool for Slip-type Downhole Throttle[J]. 2010, 39(12):81-83

[4] SHI Hua, Li Tiantai, MO Yuanzhe, YAO Ruifeng, Technic parameter determination for downhole chock in sulige gas field[J]. 2010, 29(5):45-49 